\title{
EL TEMA DEL HOMBRE EN MARÍA ZAMBRANO
}

\author{
María José Clavo Sebastián* \\ Universidad de La Rioja
}

\begin{abstract}
RESUMEN. Frente a la descripción existencialista de la estructura y actividad del ser humano, María Zambrano propone una dinámica diferente. Para el existencialismo elegimos en cada momento con vistas al ser que todavía no somos, en esta tensión nos vamos haciendo. Esta búsqueda del ser es, para María Zambrano, la manifestación de la necesidad de encontrar nuestra identidad perdida, de completarnos porque estamos escindidos. La escisión consiste en la separación entre conocimiento y vida introducida por la conciencia.Esta ruptura no puede ser superada hacia afuera. Existencia es siempre el ser fuera del sujeto, nunca identidad, lo que le sustenta es precisamente la dicotomía conciencia-ser.

La escisión, por el contrario, puede ser superada desde dentro porque nuestro ser está en nosotros, basta dejarle emerger a una conciencia abierta (razón poética) para que se constituya una simbiosis activa de conocimiento y vida transformadora y creadora.
\end{abstract}

ABSTRACT. Against the existentialist description of the structure and activity of the human being, M.Zambrano proposes a different dynamisme. For the existentialism we elect at any moment trying to make the hunan being we aren't yet, and, this way, we go on making ourselves. This search of the being is, for M. Zambrano, the sign of the necessity of finding our lost identity, of completing ourselves because we are in excisión. The excisión consists of the division between knowledge and life introduced by the conscience. This rupture can't be overcome outwards. Existence is always the being outside of the person, never identity; what mainiains it is precisely the dichotomy conscience-being.

The excision, on the contrary, may be overcome from inside because our being is in ourselves. It's enough to let it emerge to an open conscience (poetic reason) for creating an active, trasformer and creative symbiosis of knowledge and life.

\section{PRÓlogo}

Leer a María Zambrano con la intención de captar sus conceptos y analizarlos,

* Dra. María José Clavo Sebastián. Profesora Titular de Filosofia del Centro de C.C. Humanas, Jurídicas y Sociales. Universidad de La Rioja. Dirección: Vara de Rey n $77,8^{\circ}$ C. 26002 Logroño. Teléfono 238563. 
precisar su contenido y buscar una fundamentación sistemática para ellos no es una tarea fácil. María Zambrano hace poesía con la filosofía, juega con ella, pero sin hacerle perder ni un ápice de todo su valor. Muestra poéticamente las vivencias que suscita en nosotros lo real, lleno inevitablemente de categorías filosóficas.

Este juego de pensamiento y sentimiento, entre los que establece una dialéctica, resuelta, por otra parte, por ella misma en su modo de expresión, es posiblemente uno de los elementos que profundamente caracterizan su filosofía.

Lo cierto es que si ella escribe filosofía de este modo es porque algo de la realidad ha descubierto a través de la literatura: la idoneidad del lenguaje poético para encontrar y transmitir realidades metafísicas.

Del mismo modo que Nietzsche, María Zambrano piensa que el ser no posee una estructura racional, que la conceptualización del mismo se debe a que proyectamos sobre él el modo de ser de nuestra razón. Ser y razón no están constituidos por esquemas semejantes. Por lo tanto no son los conceptos, juicios y razonamientos, productos de la actividad racional, los vehículos más adecuados para la transmisión de aquello en lo que consiste el ser.

Tratándose del hombre, tema central en María Zambrano, constituido, como está, en su aspecto más definitivo por su mundo irracional, inconsciente, por sensaciones y sentimientos que son la energía que mueve la mayor parte de su existir, el lenguaje poético, en cuanto que contiene un elemento esencial de irracionalidad, es apreciado como el modo de expresión más fiel a la realidad que pretende transmitir. Ambos: hombre-poesía están integrados por lo racional y lo irracional y esta coincidencia es el motivo por lo que el lenguaje poético es el elegido por María Zambrano para hacer antropología filosófica.

Abundaremos más en este tema cuando tratemos de la razón poética: el método filosófico de María Zambrano.

\section{PUNTO DE PARTIDA:}

\section{UNA FILOSOFÍA DE CRISIS. RECUPERACIÓN DEL HOMBRE.}

María Zambrano distingue en lo referente al ser humano dos dimensiones que denomina respectivamente "lo humano" y "el hombre". "Lo humano" nace en Grecia en el momento en que la sabiduría se convierte en filosofía: en que lo que se sabe se hace problema. Este hecho supone un cambio profundo de actitud. El hombre griego confía en su razón como instrumento de conocer, lo cual,simultáneamente, conlleva la creencia en la transparencia racional del objeto de conocimiento. Así pues, viviendo de estos dos supuestos: la confianza en su razón y la estructura racional de lo real genera una actitud de protagonismo ante el mundo porque ya no necesita las explicaciones de las teogonías y los mitos para orientarse en él, sino que, a partir de ahora, se bastará a sí mismo. De este modo no sólo se le hace transparente el mundo circundante sino también su propio mundo interno. El hombre como objeto de conocimiento adquiere una estructura clara, comprensible y armónica, participa de la unidad del ser y es consciente de su propia identidad. Esta concepción de lo humano se da tanto en el plano teórico como en el de la ética y la acción y permite construir una teoría general acerca de su esencia. A ello María Zambrano lo denomina "lo humano". 
Junto a este aspecto tranquilizador, inteligible y controlable encontramos otro casi opuesto que la autora llama "el hombre" y que es la vertiente del vivir concreto, de la existencia intransferible, de la individualidad irreductible, de lo contradictorio, de lo subjetivo, de lo irracional. Desde un punto de vista histórico este aspecto es el primero vivido. La realidad para el hombre primitivo era lo sagrado. Lo sagrado se manifiesta en lo divino en instantes privilegiados, exaltados y fugaces. La realidad, por tanto, es hermética y el hombre a su vez, se siente inseguro y humillado por lo desconocido.

La filosofía saca al ser humano de este estado. Conoce la manera de que la realidad deje de ser opaca y la convierte en accesible y de este modo libra al hombre de su situación de sumisión ante lo ignorado.

En los momentos de crisis en que lo humano peligra de ser "deshumanizado", reaparece el hombre resistiéndose a la racionalización anuladora. Nuestro tiempo es uno de esos momentos porque vivimos en una época construida sobre los supuestos del logos cartesiano, científico e histórico bajo los cuales la consideración de lo individual apenas tiene cabida.

La concepción cartesiana del ser está fundada en la existencia en él de elementos estructurales estables que le dotan de consistencia y estabilidad ontológica, lo cual posibilita la constitución de la certeza, categoría desde la cual entiende la realidad la Edad Moderna.

La razón histórica impone una transformación a esta idea en el sentido de que niega las estructuras estables del ser porque lo fundamental ya no es la estabilidad sino el movimiento, El ser es movimiento, no está sino que evoluciona. La única connotación que asume del ser cartesiano es que la evolución la concibe como atenida a determinadas leyes necesarias y reconocibles; esta necesidad habida en el movimiento del ser es lo que en él hay de estabilidad y permanencia.

Tanto el logos cartesiano y científico como la razón histórica reducen la realidad del hombre a su ser objeto (exterioridad y número) al que acceden utilizando una metodología propia de análisis objetual.

La admiración por el saber positivo generador de la tecnología, la sociedad masificada por los medios de información, el consumo y el culto al progreso material constituyen una buena muestra de nuestra herencia. El hombre corre el peligro de ser absorbido en el mecanismo de la producción.

"Es ineludible y urgente reabsorber la deshumanización en una humanización más amplia...conjugar en una forma inédita lo humano y el hombre; todas las ganancias del conocimiento con la modesta vida del hombre sujeto a la necesidad y espoleado por la esperanza"l.

Así pues, María Zambrano se propone llevar a cabo una recuperación del hombre en un saber producto, no del logos cartesiano ni de la razón histórica, sino de las experiencias básicas de la vida humana, no racionales y difícilmente racionalizables.

¿A qué experiencias humanas básicas se refiere cuando habla de la recuperación del hombre? Ella piensa que debe ir a buscarlas allí donde el hombre es hombre en estado puro sin mezcla de "lo humano", es decir, en el nacimiento de la humanidad, antes de que la filosofía esclarezca racionalmente la realidad. Nuestra autora ve así el nacimiento

1. ZAMBRANO, M.: "Sobre el problema del hombre", Anthropos, Suplementos, 2, 1987, p. 102. 
del hombre:

En los primeros momentos su experiencia debió darse a nivel de sensaciones sin objetivar. El sentimiento básico probablemente fue el de sentirse perseguido por algo o alguien desconocido, debido a la proyección de la propia autopercepción sobre las cosas, incapaz de situarla dentro de sí mismo. También, bajo esta experiencia primera debió latir la sensación de extrañamiento de sí mismo en relación con lo que le rodeaba.

Por otro lado no había desarrollado todavía la capacidad de discernir unas cosas de otras, no hay nombres, pues, sólo sensaciones, su mundo era caótico. Tuvo que transcurrir un largo periodo evolutivo para que fuera capaz de diferenciar e identificar los objetos como unidades cualitativas separadas por un espacio.

El hombre comienza a ordenar su mundo cuando puede inventar dioses, es decir, a conferir algún tipo de entidad a aquello por lo que se siente mirado y perseguido. De modo que cuando en el universo del ser humano aparecen los dioses con figura y nombre aparecen también, las cosas y los seres. Este discernimiento es anterior y preparatorio al discernimiento lógico en el que se da ya una clasificación de los seres. En todo caso, desaparece el caos y el hombre conquista alguna orientación en su vida, termina el sentimiento de persecución y, por consiguiente, el continuo temor porque ahora ya tiene localizado quién le ve y ello le permite entrar en contacto con él. La función de los dioses es la de hacer posible el trato con la realidad.

La existencia de una realidad no humana encontrada es la matriz de toda otra realidad, origen del carácter real de todo lo que es. Para el hombre primitivo la realidad noes una cualidad sino algo anterior a las cosas, donde radica la vida, una realidad oculta y fundante: es lo sagrado. Así, lo sagrado otorga realidad.

La idea de realidad fundante se formó antes de la invención de los dioses porque la sensación primera de persecución tuvo que estar acompañada de la pertenencia a aquel que controlaba con la mirada y esta experiencia personal proyectada al resto de los seres es lo que generó la idea de lo sagrado.

La aparición de los dioses supuso la posibilidad de preguntar. Para poder preguntar es preciso tener presente no sólo lo que se es sino también lo que no se es. Siempre se pregunta por algo que no se conoce pero de lo que se tiene una acierta noción. Por tanto el hombre puede preguntar cuando llega a tener conciencia de su no-ser o de su no-saber. Preguntar no es sólo concretar, nombrar y dar imagen sino que nace de la capacidad de extrañarse, origen de la filosofía y se puede considerar como lo más humano del hombre.

El desarrollo de la capacidad de preguntar lleva consigo el nacimiento de una actitud nueva, de una revolución interior: la aparición de la conciencia.

La conciencia es una ruptura interna, es el ámbito que refleja.

La primera pregunta que debió formular el hombre primitivo "dirigida a la divinidad ha sido la angustiosa pregunta sobre la propia vida humana", no sobre las cosas o sobre cuestiones de conocimiento en general.

Así pues, el desarrollo y configuración de lo humano y su existir se genera por la relación del hombre con sus propios límites, con lo irreductible a él mismo. A este

2. ZAMBRANO, M.: El hombre y lo divino- México, Fondo de Culura Económica, 1986, p.35. 
encuentro con "lootro" MaríaZambrano lo llama encuentro con lo "divino": "Esta sería, quizá , la definición más amplia de lo divino: lo irreductible a lo humano, configurado de diversas maneras según sean los aspectos que eso divino haya tomado, según sean los afanes y anhelos del hombre"3.

Estas vivencias primeras constituyen la relación del hombre con lo "heterogéneo" frente a la relación racional con la realidad que se caracteriza por la aprehensión de la identidad del ser. A ellas María Zambrano conficre un alcance metafísico que las sitúa en el nivel epistemológico propio de la filosofía y los problematiza desde una perspectiva transempírica que las dota de un gran interés.

Todas las formas de racionalismo e idealismo con su idea de que la razón lo penetra todo no pueden considerar aquellos aspectos de lo real opacos o resistentes a la racionalidad y de este modo el hombre, reducido a conciencia, empobrece su contacto con la realidad ya que su conocer se limita a ser un conocer racional.

Este hecho implica consecuencias de gran trascendencia, porque no sólo determina la cantidad y calidad de realidad con la que puede entrar en relación el hombre sino, sobre todo, determina la raíz metafísica de la vida humana: su modo de inserción en el Universo.

La realidad está compuesta, según decía Ortega, por lo que es y por lo que hay pero que aún no es o que simplemente no es. El hombre cntra en contacto de muchas maneras con la realidad que no posee la categoría del ser.

"A pesar del descubrimiento del ser y del pensar la vida humana estaba durante todos estos siglos enclavada en la realidad de diversas maneras... el pensar capta el ser y deja fuera lo que es a medias, lo que es y no es: lo que no puede entrar bajo el principio de contradicción... el pensamiento unifica todo lo que conoce... esto quiere decir que aquello que hay y no es, en cuanto que de algún modo afecta a nuestra vida, no tendrá ante nuestros ojos una continuidad... este reino: el de la realidad sin ser es el de la cualidad simple"4.

Cualidad es el nombre que María Zambrano da a aquello que por no ser no tiene nombre, por ello le parece inadecuadamente racionalista darle esta denominación, pero es lo que nos puede sugerir aquel aspecto de lo que nos rodea con el que contactamos de una forma no racional.

La cualidad es una pura actualidad, se nos hace presente sin un fundamento, sin una explicación suficiente "parece estar rodeada de un abismo"5 "La situación del hombre post-cartesiano y post-hegeliano es la de aquel que, creyente en la razón como único medio de relacionarse con la realidad, se ve en la vida real rodeado de semiseres (la cualidad es un semiser ya que no puede estar suelta) irreductibles a razones, se ve acechado por cosas que no son y que aparecen inconexas, es decir por ese mundo de lo monstruoso que el arte lograba de algún modo apresar. El mundo que se había llamado de la fantasía"

\footnotetext{
3. Ibid., p. 136.

4. Ibid., p. 196.

5. Ibid., p. 196.

6. Ibid., p. 196.
} 
En todo caso, parece imposible llevar a cabo una adecuación entre racionalismo idealista y vida. La absoluta racionalidad de lo real, la identificación sujeto-objeto, es irrealizable viviendo, y es que el ser humano posee un fondo insobornable a los esquemas de la razón, un fondo último del vivir, que María Zambrano llama "entrañas" donde se encuentran todas las formas del sentir. En él se siente instante a instante el pasar de la vida, es un "padecer" que constituye lo más íntimo: se padece porque se está vivo o se está vivo porque se padece; se siente sin interrupción por el simple hecho de estar vivo. Este sentimiento profundo no puede ser reducido a la razón. Y lo que se siente es lo que no es, lo otro, lo heterogéneo, lo cualitativo, lo que no se puede nombrar porque "sólo se puede decir lo que de algún modo es" .

En los tiempos en que se pretende un "saber absoluto", todo esto (lo que no es nombrado) queda disuelto. Por eso no es posible vivir el racionalismo.

La vida humana es un deseo de visibilidad rodeado de alteridad, de aquello que está en un plano diferente al de la conciencia: "lo otro", lo "no idéntico".

"No somos sólo sujetos de conocimiento... somos un punto de identidad rodeado de lo que no la tiene... actualidad combatida por el tiempo, impasibilidad que ha de responder por algo que vive bajo ella y que es continuo, inacabable padecer. El que un hombre como sujeto de conocimiento no exista en estado de perfecta pureza y aislamiento... el que se levante entre la enajenación permanente que es el vivir, es el hecho, el simple hecho de la vida humana"s.

\section{EL HOMBRE EN IDENTIDAD CON SU SER: EL MITO DEL PARAISO}

Heidegger nos habla del hombre como Dasein, para designar aquel comportamiento humano con el ser que caracteriza la constitución fundamental del hombre.

María Zambrano considera al hombre en cuanto Dasein como realidad escindida, nacida de la conciencia, la cual engendra la distancia entre conocimiento y vida, pensar y sentir, yo y ser.

Esta escisión caracteriza una situación derivada de un supuesto estado originario de inmediatez en el que se simultanean acción, pensamiento y sentimiento en un sólo acto, en el que no se precisa la diferencia ontológica, ni la trascendencia, ni el tiempo ya que coincidían ser y estar, ente y ser.

-Las características fundamentales del ser del hombre en identidad consigo mismo a partir de las del hombre escindido son:

Trascendemos nuestro propio ser por la conciencia que de él tenemos, este hecho impide nuestra identificación con él. La presencia a la conciencia de nuestro ser se concreta en una "auto imagen". El hombre no escindido, en el que no se da la dualidad sujeto-objeto, es un ente identificado con su imagen.

En este contexto, María Zambrano utiliza figuras de "horizonte", "obstáculo" y "camino" como constituyentes existenciales no presentes a la realidad del hombre en

7. Ibid., p. 195.

8. Ibid., p. 196. 
identidad con su ser:

"¿Había horizonte?... el horizonte se constituye en un "más allá" del obstáculo primero a franquear. El obstáculo inicial podría ser nombrado, pues que inicia un modo de vida diferente, lo que se repetirá en cada vida individual, $y$, entonces, del horizonte aun solamente vislumbrado, nace el camino. Se da el camino entre algo más allá y algo que se interpone. Más dado o buscado, el camino se tenderá siempre así. Aparece cuando el centro no se muestra en modo patente". . Desde el punto de vista de la existencia el horizonte tiene el significado de aquello último a lo que aspiramos, es, pues, la presencia en nosotros de la ausencia de nuestro ser deseado que trasciende, por tanto, lo que actualmente somos. Para alcanzarlo debemos salvar determinados obstáculos. Obstáculo inicial que origina un modo de vida diferente se presenta como posibilidad de ser. Ello supone la presencia del no-ser en el ser que es lo que caracteriza el modo de ser de la existencia del hombre como posibilidad. El hombre entendido como identidad consigo mismo excluye el modo de ser como posibilidad porque estaría constituido como el serya. La noción de obstáculo implica el querer ser y no poder, por tanto el desdoblamiento y el tiempo que María Zambrano llama "camino" en tanto que une el ser que somos con el que todavía no somos. Frente a la noción de horizontc el hombre no escindido está en un centro, en un aquí y un ahora concreto pero sin tales nociones de aquí, ahora y concreto.

La situación inicial modifica, en relación con la nuestra existencial, la noción de "alteridad", la cual hace relación a la idea del "yo mismo", ya que surge de la comprensión de "lo otro que yo". Esta se entiende desde la apertura del ser consistente en un ocuparse con lo que no es él, a lo cual instrumentaliza en función suya. Pues bien, esta consideración de los seres como "lo otro que yo" no puede darse en un ente en el que le falta la presencia a sí de su ser propio. "Es la imagen que cada criatura tiene de sí, extremadamente en el reino de lo humano, el primer y más continuo obstáculo entre ella y los demás, y mayormente aún de aquellos que más le afectan. La interposición de la propia imagen convierte a toda presencia en alusión de ensalzamiento o reproche, la reduce y humilla a ser, ante todo y a veces no otra cosa que esa alusión, que ese signo que quien lo recibe le confiere.

Y entonces, al no existir la imagen propia, tampoco surge la imagen de lo demás, que nunca puede llegar a ser "lo otro". La ausencia de imágenes delata, en este caso, incapacidad de alteración y, en consecuencia, evita que aparezca la alteridad"10.

La realidad, por tanto, es el lugar de la diversidad de seres, cada uno en su unidad, co-presentes, sin ocultación de lo interior ni anterior. Lo que es se agota en su ser presente.

En esta situación no cabe lo abstracto ni lo universal ni lo causal. No puede haber proyección de nuestro aparato trascendental sobre los seres de la realidad, es decir, no hay un "horizonte" entendido como el punto nuclear que determina nuestra interpretación de lo real, por ello tampoco se da una cosmovisión que trascienda nuestro puro

9. ZAMBRANO, M.: “Acerca del Método. La balanza”, Anthropos. Suplementos 2, 1987, p. 128.

10. Ibid. 
entorno perceptivo, ni especial significado de nuestra circunstancia concreta en coherencia con nuestra concepción global de la realidad, porque todas estas cosas conllevan la noción de un "más allá" del aquí y el ahora.

Estas ideas que trascienden lo concreto sólo pueden ser producidas por el modo de ser de un ente que se trasciende a sí mismo, porque este hecho es el que hace posible la doble trascendencia de lo real en sincronicidad (espacio) y diacronicidad (tiempo).

El espacio y el tiempo son funciones subjetivas que hacen su aparición en el inicio de la existencia. La realidad entonces se constituye como tal en tanto inter-posición: el espacio como distancia que separa, el tiempo como dis-continuidad interna que constituye la existencia.

No podemos tampoco hablar del conocimiento sino de revelación, porque conocer es buscar, ya que en él lo presente hace mención de lo ausente, es, por tanto, acción. Revelación es la presencia del ser que se agota en su ser presente; es dar y recibir, por lo que se hace en pasividad.

Antes de todo esto está la palabra, "el verbo inicial", en ella se encuentran las esencias como pensamiento que se encarnan en las criaturas: esencias y formas sustancializadas.

La palabra es, pues, el ser suficiente, el pensamiento total, el ser completo; el hombre recibe su ser al recibir la palabra, por tanto, no surge como un proyecto,no tiene que crecer ni hacerse, sino que está en su ser, su ser se identifica con su estar.

La palabra primera es auténtico conocimiento, porque en él se da una simbiosis de conocimiento y vida, es conocimiento activo y creador.

La serpiente en el paraíso significa el despertar de la conciencia; ella abre el camino de la autopercepción; gracias a clla el hombre se da cuenta de sí mismo y de su situación, de su poder ser y de la alteridad, es decir, a través de ella el hombre protagoniza un trastocamiento de su estructura ontológica anterior y comienza a existir.

"Mas aquel que profirió la palabra irruptora tenía forma de sinuoso camino. Enrollada al Arbol de la Ciencia, era cifra y compendio de un indefinido camino a recorrer que se ofrecía así, sin desplegarse.

El laberíntico camino de la humana historia, en incesante búsqueda de la perdida inocencia"11.

\section{EL PROBLEMA DEL HOMBRE Y LA FILOSOFÍA}

Así María Zambrano enfoca el problema del hombre como el problema de un ser en busca de su identidad perdida.

Este es el sentido profundo de la filosofía, siempre en busca del conocimiento suficiente que dé cuenta de lo que nos falta, buscamos completarnos. La falta de íntima relación entre conciencia reflejante y vida nos hace sentir que carecemos de algo fundamental que se expresa en el "conocimiento buscado".

El entendimiento "sale de las entrañas, todo lo que constituye lo interno del hombre,

11. Ibid. p. 129. 
sale de ello y se queda solo frente a ello.

Proceso inevitable, por lo que sabemos, parte del proceso mismo de la filosofía que luego ha de reunirlos (entendimiento-entrañas), este es el sentido último de su andar en busca"12.

De modo que no es inicialmente cuestión sólo de conocimiento, sino de actualidad del ser humano como ser vivo completo, funcionando con sus elementos bien engranados.

Esta carencia fundamental que incide directamente sobre nuestro ser tiene su expresión en la existencia de una forma más directa e inmediata que en la filosofía. Se explicita en el modo de ser del hombre como existente, siempre en tensión hacia cl futuro tratando de ser el ser que todavía no es, en la continua presencia, por tanto, de su falta de ser. Esta dinámica no es sino la expresión del modo de ser de un ente incompleto, roto y escindido.

\section{ESTRUCTURA Y DINÁMICA DEL SER HUMANO}

María Zambrano distingue en el ser humano tres niveles, de ellos los dos primeros constituyen su ser escindido y el tercero la posibilidad del encuentro con uno mismo: la "recuperación" de la identidad perdida.

Al primer estrato lo llama "psique". Coincide con la noción del mundo inconsciente del psicoanálisis. Es la parte irracional del hombre.

\section{a) La psique}

Nuestro conocimiento de la psique ha sido posible gracias al estudio de los sueños. Desde un punto de vista formal conocemos su estructura mediante el análisis fenomenológico de los mismos. En esta perspectiva el sueño ofrece una gran ambigüedad. Nos presenta una realidad fenoménica de nosotros mismos, en el sentido de que en ellos se muestra nuestra vida como un espectáculo al que asistimos y de este modo ocurre que, siendo lo más espontáneo, inmediato y subjetivo de nosotros mismos, es, sin embargo, al mismo tiempo, "objeto" o, mejor dicho, es "objeto" cl aspecto de nuestra vida que en ellos se nos ofrece, porque es independiente de nosotros, ya que no podemos actuar sobre él.

Constituye un acontecimiento en el que sujeto y objeto son una misma cosa.

Otra importante característica es que el contenido de los sueños no suscita en nosotros ninguna pregunta, por el contrario, nos sentimos sumergidos en ellos como si fuera lo más natural, aunque el argumento nos cause ansiedad y angustia. Comprendemos su sentido, pero no nos hacemos cuestión de él mientras soñamos, tampoco adoptamos una postura subjetiva en relación con él (ello implicaría cl establecimiento de una distancia entre sujeto y objeto), por lo que no cjecutamos ninguna acción, nunca somos sujetos activos, ya que las acciones que ocurren en los sueños no son consecuen-

12. ZAMBRANO,M.: "La respuesta de la Filosofia", Anthropos. Suplementos, 2, 1987, p. 120. 
cia de nuestras decisiones.

Mientras soñamos estamos sumergidos en el tiempo, pero sin poderlo usar. "No tenemos tiempo". La estructura del tiempo es compacta, en ella no podemos entrar. La conciencia sólo asiste como espectadora a aquello que está sucediendo, a pesar de que sea algo tan íntimo como la sensación de un deseo.

Nuestro inconsciente es un mundo en el que todo está presente formando una unidad atemporal, en los sueños emergen partes de este universo adoptando, sin embargo, ante la conciencia una forma temporal sucesiva. Son estos sueños los más elementales, vehículo de íntimos sentimientos de frustración. El que se sitúa en el nivel más bajo es la pesadilla cuya peculiaridad estriba en las fuertes sensaciones de angustia, miedo, ansiedad etc. que produce. Su expresión es puramente cmocional: la queja, el grito.

Son sueños sin palabras porque son, como dice María Zambrano, "sueños llenos" en los que el sujeto se encuentra totalmente sumergido en una situación. La palabra, para generarse, necesita un espacio y una pausa en el tiempo: un orden espacio temporal, es decir, necesita o surge al mismo tiempo que la realidad se objetiva.

Para denominar este mundo subconsciente María Zambrano utiliza unos términos que poseen gran fuerza semántica:"ínferos', "entrañas", "nudo de víboras" etc. y, a pesar de ser el nivel menos "personal" de nosotros mismos, sin embargo desempeña un papel esencial en la antropología zambraniana ya que que en él sitúa la sustancia de la persona, aquello a donde hay que ir a buscar y extraer cl auténtico ser sí mismo de cada cual como más adelante veremos.

\section{b) La conciencia y el ser de la persona.}

\section{Elementos comunes:}

María Zambrano lleva a cabo el desarrollo del contenido de estos estados contando con las características de la estructura del ser del hombre que podemos apreciar en el existencialismo, sin embargo no explicita en sus escritos tal estructura ontológica, sino que lo que describe es el modo humano subjetivo y multiforme de vivirla.

Tal vez, la estructura de la vida humana de María Zambrano encajaría con lo que J. Marías llama la estructura empírica: una zona intermedia entre lo ontológico y lo propiamente óntico, porque nos habla, desde luego, de elementos empíricos, pero estructurales, es decir, no casuales, sino previos a cada biografía concreta, que están ya ahí funcionando como supuestos.

El problema se plantea en lo imprescindible que sea considerada para el hombre tal estructura o algunos elementos que la integran. Concretamente habría que analizar cuál es el significado del elemento del lo irracional para nuestra autora: si lo concibe como un ámbito del que se podría prescindir sin dejar, por ello, de ser hombres (y por lo tanto, como ingrediente de una estructura empírica) 0 , por el contrario, el hombre sólo puede ser entendido como tal desde su actividad emocional, de ser así pasaría a formar parte de la estructura ontológica. Aunque falta una investigación seria sobre este tema (como sobre casi todos los temas de la filosofía de María Zambrano), pienso que en tanto que 
el mundo irracional es uno de los polos que forman parte de la dinámica de la que surge el ser de la persona, debe ser considerado como un elemento constitutivo, imprescindible, por tanto, del ser del hombre.

En todo caso podemos exponer la antropología zambraniana a dos niveles. En primer lugar al nivel en que ella lo expone, que es fundamentalmente un nivel vivencial, como anteriormente hemos dicho, casi psicológico, si no fuera porque le da una perspectiva filosófica en cuanto al tratamiento epistemológico de su objeto y a la metodología fenomenológica que utiliza para abordarlo. En segundo lugar, a nivel ontológico, explicitando lo que en sus descripciones se encuentra implícito: la estructura existencial del ser del hombre como el a priori que funda y que, por tanto, permite una más amplia visibilidad en el entendimiento de la vida interna del sujeto.

Diversos aspectos complementarios integran estos estados:

- La temporalidad.

- La no identificación del hombre con su ser.

- Nuestro ser-en-la-realidad.

\section{Temporalidad:}

La psique es atemporal, la actividad de la conciencia, sin embargo, está relacionada en sí misma con el tiempo, porque éste forma la estructura esencial de la subjetividad

El tiempo es intuición pura y condición de la sensibilidad interna, en tanto que pura no procede de ninguna manera de nada que esté "fuera", sino que forma de modo activo y espontáneo la sucesividad y se pro-pone a sí misma este aspecto como tal. Por tanto, como afección pura, forma la esencia de un concernirse a sí mismo, cosa que es también la esencia de la subjetividad ${ }^{13}$.

En cuanto condición de la sensibilidad interna la conciencia se vive en una dinámica sucesiva.

A partir de aquí podemos entender que María Zambrano afirme que el tiempo fluye de la conciencia, porque la conciencia, en tanto subjetividad es tiempo, lo que define formalmente todas sus actividades.

Como consecuencia de la actividad consciente se disuelve la simultaneidad característica de los contenidos de la psique y al mismo tiempo se aclara la ambigüedad inherente a ella: su ser sujeto-objeto al mismo tiempo.

La separación sujeto-objeto se manifiesta a partir de la actuación del sujeto en sus momentos o instantes propios: "estar frente a" "tomar posición" y "decisión". En este proceso hay una "antes", un "vacío", instante en el que no acontece nada material, sólo el movimiento del sujeto como tal, seguido de un acontecimiento material.

El tiempo, que para Kant es un elemento trascendental, condición de posibilidad de nuestra experiencia, en María Zambrano es el apriori del argumento en que consiste la vida humana, funciona como el principio de organización cuya materia es el contenido

13. HEIDEGGER, M.: Kant y el problema de la metafísica.- México, Fondo de Cultura Económica, 1981, p. 161-162. 
concreto de cada biografía, por tanto constituye no el argumento, ni el sentido, sino el modo de vivirla. En el tiempo la vida se sustantiva, del mismo modo que la materia cognoscitiva adquiere figura en los apriori espacio-tiempo. Esta es la razón por la que la fluencia del tiempo coincide de modo trascendental con la condición perecedera de la propia vida humana, ambas constituyen el horizonte del nacer (desde un pasado), del crecer (del ir haciéndose) y del morir (hacia un futuro).

La estructura temporal de nuestra existencia nos permite trascender nuestro ser óntico y explica otra de las funciones zambranianas del tiempo: el ser el camino, el medio que se le ofrece al hombre para poder ir alcanzando el ser que desea ser desde el ser que es.

El hombre entendido esencialmente como tensión "hacia el futuro" implica, como todos sabemos, una transformación de la noción parmenídea del ser que María Zambrano expresa de este modo: "El ser ha mucrto, el hombre es su heredero"14 $\mathrm{o}$ "El camino del tiempo pasa arrasando el ser: el scr en cuanto tal y el ser de aquel que por él transita" el hombre, a lo que sabemos"15.

El que sintamos o vivamos el tiempo es, lógicamente, la consecuencia empírica de la constitución tempórea del yo. La vivencia del tiempo está entrelazada con la vivencia de nuestro propio ser y en ello confluyen multitud de elementos irracionales. Nuestra autora escribe mucho y largamente acerca de los "múltiples tiempos" en los que el hombre vive como uno de los factores decisivos en el establecimiento de la dinámica de cada cual en su existir.

La no identificación del hombre con su ser:

La vida, dice María Zambrano, nos es dada, pero hay que hacer el vivir. El hombre recibe su vida (en sentido biológico) y con ella su ser, a él está referido, en realidad el hombre es "relativamente a su ser", porque cada una de sus acciones se ejercitan con vistas a ser lo que va a ser. Ello significa, por un lado, la constante presencia cognitiva del ser y, por otro lado, la existencia como modo de ser del hombre.

Ortega considera el primer atributo de la vida la transparencia: "todo vivir -dice-es vivirse, sentirse vivir, saberse existiendo- donde saber no implica conocimiento intelectual ni sabiduría especial ninguna, sino que es esa sorprendente presencia que su vida tiene para cada cual...

La piedra no se siente ni sabe ser piedra: es para sí misma, como para todo, absolutamente ciega. En cambio vivir es, por lo pronto, una revelación, un no contentarse con ser, sino comprender o ver lo que se es, un enterarse". ${ }^{16}$

En María Zambrano la "comprensión del ser" heideggeriana está formulada como el momento en que la naturaleza se sabe a sí misma: la aparición de la conciencia. Esta produjo una escisión interna en el ser humano distanciándole de su ser y este distancia-

14. ZAMBRANO, M.: El sueño creador.- Madrid, Tumer, 1986, p. 45.

15. Ibid. p.50.

16. ORTEGA Y GASSET, J.: ¿Qué es Filosofía?.- Madrid, Revista de Occidente, 1958, p. 228-229. 
miento conlleva consecuencias existenciales que anteriormente ya hemos mencionado.

El resto de los seres de la naturaleza no han despertado; no están, por tanto, escindidos; más que existir, son.

"El astro es sólo criatura que obedece, pensamiento de la creación, manifestación del ser; figura, eidos...Y la planta, que tiene ya que hacer algo, pero siempre en obediencia, se soñará a sí misma en el cumplimiento de su forma, obedeciendo y aún identificándose con su sueño"17.

La constante presencia de nosotros a nosotros mismos da sentido al posesivo mí: yo soy dueño de mi ser...vida...existir. En cada momento poseo mi ser propio porque mi propio ser es ante todo posibilidad.

"Y por ser en cada caso el "ser-ahí" esencialmente su posibilidad, puede este ente en su ser elegirse a sí mismo, ganarse y también perderse, o no ganarse nunca o sólo "parecer ser que se gana". Haberse perdido y haberse ganado sólo lo puede en tanto es, por su esencia misma, posible "ser-ahî", "propio", es decir, apropiado por sí mismo y para sí mismo"18

Este carácter de posesividad del propio ser junto a que éste es esencialmente posibilidad, es el fundamento ontológico de las descripciones que lleva a cabo María Zambrano acerca de la dinámica del hombre con su ser en las cuales explicita diferentes formas de vivir la trascendencia. De nuevo subjetiviza la estructura metafísica hablándonos de la vivencias que se nutren de ella.

"Siendo este su ser recibido, se lo encuentra a su cargo, lo lleva y lo soporta, lo sufre en verdad, pues que le pesa; lo envuelve y hasta puede poseerlo, si ha dejado de contar con él o si cuenta en demasía...

Encuentra el hombre su ser, mas se encuentra con él como un extraño; se le manifiesta y se le oculta; se le desvanece y se le impone; le comunica y exige...llega en ocasiones hasta negar su ser recibido...Se presenta, así, le pregunta de qué clase de ser es este propio del hombre que siente su ser... (el hombre), o bien difiere de su propio ser o bien dentro de su ser hay algo que le exige ir más al lá de él, trascenderlo, trascenderse.

Se podría así definir al hombre. como el ser que padece su propia trascendencia"19.

$\mathrm{O}$ "La vida funciona desde el primer momento entre la presencia y la ausencia, entre el ser que es ya y lo que no está por el momento, o no será quizá nunca. La presencia de la ausencia, signo inequívoco de la vida" 20 .

Podríamos decir "etc." porque las descripciones no están agotadas con estos párrafos, sólo añadir que María Zambrano entiende por libertad la posibilidad que tiene el hombre de hacer algo con su ser, derivada de su no identificación con él.

Nuestro ser- en- la- realidad:

El hombre toma conciencia de sí en simultaneidad con lo que no es él. Se encuentra

17. ZAMBRANO, M.: El sueño creador.- Madrid, Turner, 1986. p. 51

18. HEIDEGGER, M.: El ser y el tiempo.- México, Fondo de Cultura Económica, 1974, p. 54.

19. ZAMBRANO, M.: El sueño creador.- Madrid, Turner, 1986, p. 52-53.

20. ZAMBRANO, M.: "Fragmentos sobre la Naturaleza", Anthropos. Suplementos, 2, 1987, p. 89. 
entre las cosas y ante las cosas. Entre las cosas porque con ellas construye la dinámica de su vida, ante las cosas porque ellas constituyen el horizonte en el que esboza sus proyectos y posibilidades. Con su ser inacabado necesita de la realidad para "realizarse", para ir construyéndose en la dirección del "todavía no" del ser. Este es el sentido de su entrada en la realidad. "Su ser pierde, a causa de la relatividad de este camino, algo del carácter del ser, no de lo que ese ser sea, pero gane en realidad"21.

Cuando menciona "carácter del ser" se refiere al carácter de absoluto e invariable de la noción parmenídea de ser.

En cierto modo, de la realidad podemos decir lo mismo que del tiempo que ambos son camino y, en tanto tales, funcionan para el hombre entendido no como "ser substancial" sino como "existencial". Ello es consecuencia de que la existencia precede ontológicamente a ello. El hombre existe desde el ser para realizar ónticamente su vida; y para la búsqueda y el encuentro de todos los entes intramundanos, es también su existencia la que esboza previamente un mundo, en el cual cuida de descubrir las cosas y el ser de ellas ${ }^{22}$.

Por ello la realidad se le presenta al hombre como total, como imagen del mundo o visión del universo resultado de la necesaria interpretación que el ser humano lleve a cabo para orientarse, la cual mediatiza su contacto con lo real. Esta constitución trascendental del mundo humano la expresa María Zambrano de este modo:

"Mas el hombre tiene otro espacio, además de aquel donde su cuerpo se mueve. Y hasta este espacio de su ser físico depende del otro espacio, del previo, aunque conquistado tan larga y duramente. El espacio donde las cosas, las circunstancias, se revelan, se hacen visibles, donde él puede verlas y tratar con ellas. Y estas cosas le atañen, estas circunstancias resultan ser todas, como Tales dice, todas las cosas, es decir, el Universo"23

Como consecuencia de esta dependencia del mundo con respecto al sujeto podemos definirlo como aquello que le afecta. No es, por tanto, el mundo el conjunto de todas las cosas, ni tampoco la materia y el objeto del conocimiento físico o metafísico. El mundo es esto mismo en cuanto entra el sujeto que lo interpreta y vivencia, en cuanto es paraun-sujeto un campo vital no limitado por lo próximo ni lo físico, sino integrado por todas las realidades no identificables con el sujeto mismo y que de una u otra manera le afect: tanto próximas como lejanas espacial y temporalmente, físicas o inmateriales e incluso, en la medida en que el yo no puede ser reducido a cuerpo ni a alma, uno y otra forman parte de su mundo.

Hay diferentes modos de referirse a la realidad que se corresponden con otros tantos modos de donación de ésta.

María Zambrano considera dos fundamentales: el racional y el irracional, ellos determinan el modo de inserción del hombre en el Universo. Leámosla:

21. ZAMBRANO, M.: El sueño creador-- Madrid, Tumer, 1986, p.53.

22. ZUBIRI, X.: Cinco lecciones de Filosofia.- Madrid, Alianza, 1980, p. 266.

23. ZAMBRANO, M.: "Sobre el problema del hombre", Anthropos. Suplementos, 2, 1987, p. 98. 
"A partir del pensamiento cartesiano la conciencia ganó en claridad y nitidez y, al ensancharse, se apoderó del hombre todo.

Y lo que iba quedándose fuera no eran cosas, sino nada menos que la realidad, la realidad oscura y múltiple. Al reducirse el conocimiento a la razón solamente, se redujo también eso tan sagrado que es el contacto inicial del hombre con la realidad a un modo único: el de la conciencia... el hombre se tornaba en simple soporte del conocimiento racional, con todo lo que esto conlleva de extraordinario, pero la realidad en torno se iba estrechando a su compás; a medida que el sujeto se ampliaba, diríase que absorbiendo las funciones que el alma desempeñaba antes, la realidad se empequeñecía.

Pero este agostamiento de la realidad no tenía lugar de un modo uniforme, sino de un modo que ha modificado en esencia la inserción del hombre como criatura viva en el Universo. La raíz metafísica"24.

En el contexto de las interpretaciones de la realidad constitutivas al sujeto, María Zambrano lleva a cabo una exposición extraordinaria acerca de los diferentes modos de entender el mundo desde el mito y desde la filosofía. Estas interpretaciones conllevan también una interpretación del sujeto-hombre como elemento del mundo del que forma parte en coherencia con la del resto del universo. Esto supone no sólo la concepción teórica de dos tipos de hombre, sino la encarnación vital de los mismos. El sujeto se modifica, no en sus estructuras ontológicas, sí en los elementos dominantes y directivos de su vida ónticamente considerada, comunes a los de las vidas del resto de los hombres que comparten o conviven la misma idea de la realidad.

Lo que el mundo sea para el hombre es el hombre para el mundo y ello determina su modo óntico de entrar en relación con él, así como la selección de aquello que considera o no real, de ahí que pueda hablarse de mundos del hombre empobrecidos 0 enriquecidos.

\section{Aspectos diferenciales}

En la descripción que María Zambrano hace del "estado de conciencia" lo fundamental es el equilibrio del yo, en realidad ofrece muchas semejanzas con el "ego" del psico-análisis.

El yo toma posesión de la realidad y la controla, es decir, configura su mundo de acuerdo con sus propias categorías. La actividad fundamental del yo en este estado es la atención a los elementos que "acechan" a la conciencia. Sobre estos elementos lleva a cabo una selección dejando pasar a formar parte de su mundo únicamente aquéllos que cumplen las exigencias requeridas para ello. Por tanto hay realidades que quedan fuera, que no se hacen conscientes.

En el fondo la atención mantiene al sujeto en una situación de pasividad porque su actividad sirve para mantener un estado y, por lo tanto, el vivir más que vivir es un estar

24. ZAMBRANO, M.: El hombre y lo divino.- México: Fondo de Cultura Económica, 1986, p. 191-192. 
en la vida sin más. La conciencia es, de este modo, un recinto cerrado constituido por un tiempo sucesivo domesticado reducido a presente para poder ejercer sobre él una visión adecuada: el pasado no existe, para existir ha de "representificarse", es decir, hacerse presente de nuevo; el futuro queda también reducido al presente como previsible porvenir.

Ciertamente los criterios de selección de lo que puede o no ser concienciado obedecen a un aprendizaje y responden al proceso de introyección de las normas sociales y morales que el sujeto lleva a cabo a lo largo de su vida en sociedad.

El "estado de conciencia" así concebido constituye, en alguna medida, la base en la que se apoya la vida inauténtica, que María Zambrano caracteriza con el nombre de máscara o personaje, que todos consciente o inconscientemente representamos y que responde más a lo que los demás esperan de nosotros que a nuestro genuino ser nosotros mismos.

Puede ocurrir que entre nuestro ser y nuestro personaje haya coincidencia, pero también puede ocurrir lo contrario; en tal caso se genera en el interior de cada uno un conflicto interno ante el cual el sujeto puede adoptar dos posturas:

1: "No deshacer el círculo mágico del conflicto en que está apresado, sin encaminarse a traspasar el umbral de sus sueños (su "estado de conciencia") se reviste de su personaje ... en el que se oculta y exhibe a la par"25.

2: “... en la que el sujeto se desposee, se desenmascara, se va reduciendo a la unidad de su ser trascendente"26.

Esta segunda postura responde al "ser de la persona", su característica fundamental es la tensión del sujeto a ser él mismo. El paso del "estado de conciencia" al "ser de la persona" supone una transformación interna, un vivir la vida en otras dimensiones ajenas a la "domesticación" racional de la conciencia.

Nuestro mas genuino ser-nosotros-mismos está en nuestro mundo inconsciente e irracional, el encuentro con él nos hace descubrir el sentido y finalidad que nos constituye. La elección de ser-nosotros-mismos nos hace abrirnos a escuchar esa voz interna que llamamos "vocación".

Hay que hacer notar dos cosas: la no voluntariedad consciente en la posición del sentido de cada cual. Este, simplemente, está ya en nosotros, nuestra función es descubrirla. María Zambrano no entiende la vida auténtica como el camino que recorremos y en el que vamos realizando una propuesta de ser de forma personal, racional y consciente, sino como el ser fieles a nuestro ser peculiar, el cual surge a una conciencia receptiva, pasiva, por tanto. En segundo lugar la vocación de cada uno, la llamada al cumplimiento de nuestra finalidad concreta, no procede de la autointerpretación de nuestro ser-sí-mismo, sino que procede de la realidad que nos es, realidad con la que nos encontramos y que, por tanto, no depende de nuestra actividad consciente en 
su configuración, porque está antes e independientemente de tal actividad. Es concebida, pues, por María Zambrano casi como algo metafísico.

El hecho de que nuestro ser-nosotros-mismos se genere en la psique puede tener como consecuencia el que difícilmente traspase la barrera de lo consciente, rechazado por la racionalidad del yo. En tal caso únicamente podemos acceder a él a través de los sueños, que son la única presencia posible a nuestra conciencia de lo que nuestra racionalidad rechaza. Así, los sueños pueden llegar a ser el medio a través del cual entrar en contacto con nuestro ser.

Se precisa, no obstante, una determinada condición previa en el sujeto para que estos "sueños del ser" adquieran peso vital significativo: la receptividad, entendida como la actitud de aceptación de lo que está al otro lado de la razón.

- El problema de la interpretación de los sueños.

No es el argumento de los sueños el que nos conduce al descubrimiento del ser porque el argumento es perfectamente asimilable por las categorías de la conciencia, ya que es racionalidad, es, mas bien, la forma en la que se desenvuelve el argumento lo más indicativo de lo que somos. "Ambiente fantasmagórico, alucinado o incomprensible para la razón pero que está ahí, en el sujeto, que es parte de si y como tal se expresa en su propio lenguaje simbólico, ya que con el lenguaje de la razón vigilante no siempre puede hacerlo"27.

El psicoanálisis interpreta los símbolos como el vehículo de expresión que utiliza el subconsciente para manifestarse como alternativa a la censura de la conciencia racionalizadora. Para María Zambrano, sin embargo, estos símbolos son muy valiosos, no por lo que ocultan (psicoanálisis) sino por lo que revelan: aluden a una realidad nuestra a la que debemos abrirnos. "Descifrar una imagen onírica, una historia soñada, no puede ser, por tanto analizarla. Analizarla es someterla a la conciencia despierta que se defiende de ella, enfrentar dos mundos separados de antemano.

Descifrarla, por el contrario, es conducirla a la claridad de la conciencia y de la razón desde el sombrío lugar, desde el infierno atemporal donde yace, lo que sólo puede suceder si la claridad proviene de una razón que la acepta, porque tiene lugar para albergarla: razón amplia y total, razón poética que es a la par metafísica y religiosa"28.

Así podemos acceder a nuestro ser descifrando símbolos oníricos que son el medio que utiliza nuestro inconsciente para expresarse. Estos símbolos manifiestan su contenido oculto a la luz de una razón que no los interpreta, sino que respeta lo que de irracional se encuentra en ellos. (Este es uno de los aspectos de la razón poética).

Una interpretación correcta del sueño supone que la atemporalidad de la psique entra a formar parte del tiempo de la conciencia.

Es un proceso activo, en él se libera el contenido significativo de la imagen y esta liberación implica su exteriorización simultáneamente a su asimilación, tal como

27. MUÑOZ VICTORIA, F.: "Sueño y revelación" en El pensamiento de María Zambrano, Madrid, Zero, 1983, p. 94. 28. ZAMBRANO, M.: El sueño creador.- Madrid: Turner, 1986, p.77. 
sucede cuando algo íntimo antes desconocido se hace visible, la persona, en este proceso, a la vez exterioriza (libera, ve) e interioriza, asimila.

Este conocimiento nos hace presentes a nosotros mismos y esta presencia nos transforma. Es, por tanto, un conocimiento activo, viviente.

Los aspectos más profundos de nuestro ser tienen este carácter: los encontramos (tal vez a través de la interpretación de nuestros sueños), se nos revelan y en este descubrimiento concienciamos también el sentido de nuestro ser. Por eso producen en nosotros una transformación personal. Son un conocimiento creador.

Esta dinámica en que consiste el encuentro con nosotros mismos: elementos ininteligibles, íntimos, ocultos que descubrimos en la claridad de una razón amplia, que liberan nuestra intimidad y enriquecen nuestra persona, que nos muestran lo que somos y con ello nuestro sentido y que tienen un efecto transformador y creativo sobre nosotros mismos, es un proceso activo en el que no aparece la escisión habitual entre conocimiento y vida, sino una simbiosis de ambos elementos, ya que la acción de conocer es, al mismo tiempo, una acción vital. El ser de la persona, es un centro ejecutivo que busca en esta ejecución la realización de su propio ser. Es, por tanto, un yo ejecutivo al mismo tiempo de la acción de conocer y de la acción de transformarse a sí mismo.

Estos momentos que María Zambrano llama de "lucidez de la conciencia" anulan la escisión que nos constituye y nos permiten vivirnos como seres llenos, completos, integrados, en ellos se hacen compatibles lo racional y lo irracional. Por esta razón nuestra autora considera el ser de la persona como trascendente porque no coincide ni con la psique ni con la conciencia, sino que trasciende a ambos conteniéndolos.

Como podemos observar frente a la descripción existencialista de la estructura y actividad del ser humano, María Zambrano propone una dinámica diferente.

Para el existencialismo elegimos en cada momento con vistas al ser que todavía no somos, en esta tensión nos vamos haciendo. Esta búsqueda del ser es, para María Zambrano, la manifestación de la necesidad de encontrar nuestra identidad perdida, de completarnos porque estamos escindidos. La escisión consiste en la separación entre conocimiento y vida introducida por la conciencia. Esta ruptura no puede ser superada hacia afuera. Existencia es siempre el ser fuera del sujeto, nunca identidad, lo que la sustenta es precisamente la dicotomía conciencia-ser.

La escisión, por el contrario, puede ser superada desde dentro porque nuestro ser está en nosotros, basta dejarle emerger a una conciencia abierta (razón poética) para que se constituya una simbiosis activa de conocimiento y vida transformadora y creadora.

Por eso ser es emerger, surgir, nacer, expandirse, crearse. Frente a las coordenadas espacio-temporales del existencialismo que se presentan, en cierto modo, como los obstáculos que hay que recorrer para llegar a ser lo que aún no se es, el espacio-tiempo zambraniano adquiere el carácter facilitador de la emergencia y expansión del ser.

\section{5) LA RAZÓN POÉTICA: ALGUNAS NOTAS}

Los elementos que encontramos en todo tipo de racionalidad (cartesiana, instrumental, vital, etc.) son los siguientes: un afán de objetividad, una determinada concep- 
él en lo que éste tiene de único. Junto a estas coincidencias María Zambrano añade a Bergson el que la razón poética hace posible le emergencia del ser del sujeto a la conciencia propia y ello significa que se dan en un solo acto el ser y el saberse ser. Y difiere de este autor en que mientras para Bergson la razón es un auxiliar de la intuición en los sentidos de análisis y modo de expresión, para María Zambrano el captar lo real y expresarlo no tienen por qué constituir dos operaciones separadas, por el contrario, se pueden llevar a cabo en una unidad, en un solo acto, de modo que en ella la palabra es desveladora del ser, es decir, la palabra pertenece a la captación porque es el acto que revela lo que las cosas son.

Por supuesto, en sus escritos no encontraremos ningún procedimiento filosófico que se parezca al método cartesiano de análisis, síntesis, inducción o deducción, porque, como ya sabemos, el ser para María Zambrano, no posec una estructura racional, por lo que este tipo de metodología no le parece la adecuada para acceder a él.

4. Su criterio de verdad: un conocimiento es verdadero si es capaz de transformar al sujeto que lo posee.

5. La finalidad de la razón poética es la auto-creación.

Ambos coinciden en que la razón cartesiana no da cuenta de la peculiaridad de lo humano porque no contempla lo singular, lo situacional, lo irracional, subjetivo, etc..

Sin embargo difieren en su concepción del ser y, como consecuencia, en todo lo que de ella se deriva. 
ción del ser, un método adecuado para acceder a él, un criterio de verdad y una finalidad.

Para una mejor comprensión del significado de la razón poética podemos establecer una comparación esquemática entre ésta y la razón vital orteguiana, tomando como base los elementos estructurales antes mencionados.

En la razón vital orteguiana encontramos:

1. Una aspiración, por supuesto a lo objetivo, a que lo hallado posea el carácter de lo verdadero.

2. Una concepción del ser que se concreta en una dualidad de elementos: yocircunstancia, interdependientes, los cuales constituyen la vida como realidad radical.

3. Un método que consiste en respetar la presencia de lo que se presenta, y que, por tanto, no constriñe a priori el ser a las estructuras lógicas matemáticas racionales.

4. Un criterio de verdad que es la evidencia intuitiva al modo de Husserl.

5. Una finalidad que es vital, en el sentido de que cl conocimiento nace de la necesidad que el hombre tiene de orientarse en la realidad y por tanto su razón de ser es satisfacer tal necesidad.

En la razón poética:

1. Una aspiración a la objetividad, a la verdad.

2. Su concepción del ser difiere de la orteguiana, en el sentido de que la circunstancia o mundo no cumple en ella un papel tan definitivo como en Ortega. María Zambrano entiende el ser como algo bastante cerrado, parecido a una mónada leibniziana, cuya peculiaridad fundamental es la actividad creadora.

3. El método es el intuitivo, pero no al modo fenomenológico, porque en la fenomenología, aunque se defiende una interdependencia entre conciencia y fenómeno, subsiste la escisión entre estos elementos: conciencia, elemento reflejante, fenómeno, elemento reflejado.

Su método es el de la intuición de la experiencia inmediata de la conciencia .

Merece la pena mencionar aquí la comparación que establece Chantal Maillard en su libro "E1 monte Lu en lluvia y niebla"29 entre María Zambrano y Bergson en lo que se refiere al método filosófico que ambos defienden.

El conocimiento poético de María Zambrano coincide con la idea de intuición de Bergson en estos dos puntos:

1. Para ambos son conciencia inmediata en la que hay coincidencia entre objeto y visión.

2. Para ambos es simpatía. Es decir, el sujeto penetra en el objeto y coincide con 